\title{
'Crush Programme' as Part of Combined Control Programme for Culex Mosquito in Both North and South Dhaka City Corporation
}

\author{
Karim AMMN ${ }^{1}$, Afroz $\mathrm{T}^{2 *}$, Halim $\mathrm{KS}^{3}$, Begum $\mathrm{M}^{4}$, Parvez $\mathrm{TM}^{5}$
}

\section{INTRODUCTION}

There are 123 species of mosquitoes in Bangladesh, of which two types are dominant - Aedes and Culex. ${ }^{1}$ The breeding season of culex, spreading deathly diseases, is between late November and March, while Aedes aegypti, the species responsible for causing Dengue among other diseases, breeds between March and November, especially during the rainy season. The climate change has impact on increasing the mosquito's population and risk of havin gvector-borne diseases like malaria, dengue. As a new phenomenon in this current century, people living in the tropical and subtropical climates like Bangladesh are currently at high risk of dengue epidemic. About 390 million dengue infections are estimated to occur per year, among them about 60-130 million will be clinically manifested. ${ }^{2}$

In recent days, both Dhaka North City Corporation (DNCC) and Dhaka South City Corporation (DSCC) have started the 'Crush Programme' to combat the mosquito menace from $8^{\text {th }}$ to $16^{\text {th }}$ March $2021^{1}$. They have already spotted 629 breeding grounds solely in DNCC and are planning to use Novaluron there, with the rest of the city area as well. For larviciding, both city

1. Dr. Abul Masud Md. Nurul Karim, Assistant Professor, Department of Epidemiology (NIPSOM), Mohakhali, Dhaka, Cell: +8801716802553 , Email: dnurulkarim@yahoo.com

2. *Dr. Tamanna Afroz, Cell: +8801812165022, Email: dr.tamannaafroz@gmail.com

3. Prof. Dr. Kazi Shafiqul Halim, Professor \& Head, Department of Epidemiology, National Institute of Preventive and Social Medicine (NIPSOM), Mohakhali, Dhaka, Cell: +8801718227677, Email: drzimmu_nipsom@yahoo.com

4. Prof. Dr. Masuma Begum, Professor (C.C.), Department of Community Medicine, Holy Family Red Crescent Medical College, Eskaton, Dhaka, Cell: +8801711619561, Email- masuma_dr @yahoo.com

5. Dr. Tarique Mehedi Parvez, Public Health Expart, Deputy Director, Bangladesh Red Crescent Society, Dhaka

*For Correcpondence corporations are using Temephos and Malaria Oil B at the stagnant water bodies for further control of mosquito inhabitants. They are also using Malathion for adulticide. ${ }^{3}$ The concerned authority came to the decision to use this fourth-generation pesticide Novaluron (Benzoylphenyl Urea, BO urea), after considering previous efficiency of other methods based on the concept: changing the pesticides after one or two years so that mosquitoes don't get to adapt those pesticides in Dhaka. ${ }^{4,5}$

\section{BACKGROUND:}

Outdoor mosquito control measures, most commonly practiced world wide are the following:

a) General Insecticides Spraying

b) Customized Insecticides Spraying

c) General Fogger Spraying

d) Mini Fogger Spraying

e) Drains and Ponds Cleaning and Treatment, among others.

In the sixties of last century, Dhaka (previously Decca) City Corporation took initiatives to eradicate mosquitoes through Dichlorodiphenyltrichloroethane (DDT) spraying as part of "Global Malaria Eradication Programme" of WHO during the 1950s and 1960s. It was used until 2009 on national level in some countries to control mosquito. However, DDT is banned now, because: a) hazardous to human health, b) hazardous to environment causing air pollution, damaging crops, and ecological destruction of plants among others and c) hazardous to other species such as fish, cattle, wild animals etc. ${ }^{6}$

Previous research showed that Integrated Mosquito Management (IMM) could better achieved by several ecological measures: 1) seeding of drains and permanent water bodies with suitable larvivorus fish species, 2) removal of water hyacinth from urban water bodies- lakes, pond, artificial water reservoir etc. and 3) replacing them with duckweed to prevent recurrence of water hyacinth would be good control interventions in addition to the habitat manipulations, with less dependence on chemical pesticides. 
In Dhaka city a 6-week programme of cleaning drains, seeding them with guppy and use of Malariol B could give good mosquito control for several months, which was adapted by DCC during nineties for mosquito control measure. $^{7}$

Later, WHO has clarified vector control strategies in 2017's report, where suggestion is made emphasizing environment a public health concern of using any insecticide indoor or outdoor for using as larvicide or adulticide including source reduction methods ${ }^{8}$. This was highly welcomed by DNCC and DSCC at once.

DNCC has undertaken an initiative called "400-gauge by 400 -gauge", where there are supervisors to monitor the activities of workers engaged in mosquito control in every 400 square-gauge area of a ward. Presently, there are 15 workers in every ward who work with DNCC in this regard $^{1}$. Along, DSCC is planning to adapt Bacillus thuringiensis subspecies israelensis (BTI), a bacteria that will kill larvae once mixed with water. According to DNCC sources, the special mosquito eradication campaign which started on February 20, 2021 ending on $7^{\text {th }}$ March.

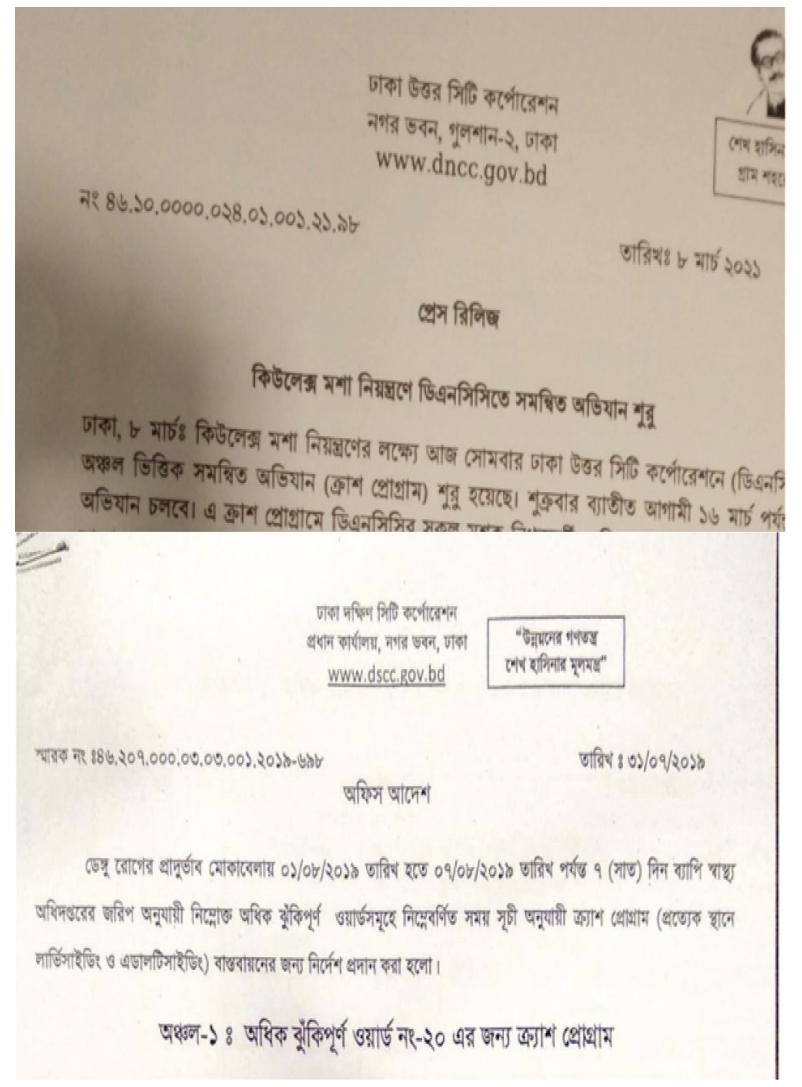

Picture 1: Screenshots of the government acknowledgement on launching 'Crush programme'. (Source- DCC website, http:// www.dncc.gov.bdl, http://www.dscc.gov.bdl)
An Integrated Vector Management (IVM) system is undergoing, entailing four elements - environmental control, biological control, larvicide and adulticide, which is mandatory to control the mosquito problem in cosmopolitan city. Within this purpose, larviciding will be carried out each day from $6 \mathrm{am}$ to $12 \mathrm{pm}$ and adulticiding will take place from $4 \mathrm{pm}$ to $6 \mathrm{pm}$ in this campaign programme. In essence, mosquito repellent is sprayed in the capital with the fogging machine weighing around 25 $\mathrm{kg}$, carried by the extermination vehicle with workers of city corporation. In addition, as a known fact, stagnant water is the breeding ground for the mosquitoes, water treatment is ongoing too. During this special operation, around 45,000 roads, sewers, water reservoirs, installations etc. were inspected. Of these, 210 were found with mosquito larvae and 30,129 mosquito breeding grounds were destroyed applying pesticides, besides taking judicial actions. ${ }^{1}$ Both Dhaka North and South health department, waste management department, and health engineering department will collaborate to ensure the successful completion of the 'crush campaign' targeting to eradicate culex mosquitoes mainly and in a continuation of the combing operation to kill the aedes aegypti mosquitoes as well. For biological control measure of the mosquitoes, DCC released fish in Dhanmondi and Khilgaon lakes so that they eat up the larvae.

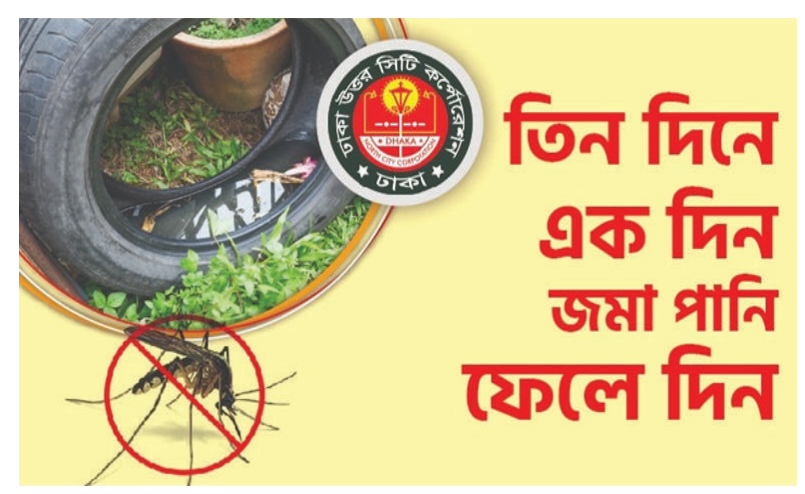

Figure 2: Poster picture of the Dhaka City Corporation. (Source-DNCC (http://www.dncc.gov.bdl)

Bangladesh has experienced horrifying dengue epidemic in 2019, where 101,354 people were hospitalized. ${ }^{9}$ Therefore, Dhaka City Corporation both North and South has undertaken an integrated mosquito eradication program that is used world wide following WHO guideline for eradication program. ${ }^{10}$ For example:

a) The insecticide in the fog is not harmful for human if used at the low concentrations. 
b) It has presumably no odour.

c) Fogging operations are conducted in the early morning or late afternoon which is also undergoing in Dhaka.

d) Citizens are advised not to be concerned about the fog or the repellent. They are requested to leave their doors and windows open when the fogging machine is in their area with repellent spraying action, so that the fog can kill mosquitoes inside the house.

e) Residents are also advised that they need to continue to prevent dengue mosquitoes breeding spots inside or around their home. ${ }^{11}$ For instance, in the stagnant water in the hidden pits, behind the window, backyards, old unused tires etc.

Public health concern; health and environmental hazards along current crush programme:

The Plant Protection Wing of the Department of Agricultural Extension and Institute of Epidemiology Disease Control and Research (IEDCR) has certified and approved the use of Novaluron as pesticide to use in Dhaka after testing. The recommendation for proper monitoring and field testing is done by public health expert in Bangladesh regarding the Novaluron. Like any tools, all pesticides and insecticides have limitations. The potential for adverse ecological and human health impacts as a result of excessive and indiscriminate insecticide use have been documented about Novaluron. ${ }^{12}$ The prescribed amount use is non-alarming and so far, the harm is avoidable. In this regard, WHO and FAO reports have not found any sizable health and environmental hazards of the pesticide. ${ }^{13,14}$ On the other hand, the effectivity of the Novaluron as larvicide for culex mosquitoes has been documented for vector control, which is rather promising in recent research. ${ }^{15}$ In addition, in current mosquito eradication program in Bangladesh, Temephos and Malaria Oil B are also used besides Malathion for adulticide.

Probable health hazards of the pesticide could include, respiratory symptoms, such as irritation, cough, runny nose, reddening of eyes etc. Children of early age could get affected negatively if get in touch of high concentration of mosquito repellents, which contains heavy to light particles. However, as part of precaution measure, asthma patients are asked to stay indoors during the 'Crush programme. ${ }^{16}$

As environmental hazards, certain types of fishes happened to die due to the Novaluron mixed in water in higher concentration. ${ }^{12}$ The Malathion is a known air pollutant in above usual level. It could produce harmful effect if used excessive amount. Concentrated amount of Temephos (aka 'Abate') could work as water pollutant and kill the flora and disrupt the homeostasis of the underwater ecosystem. Although, Temephos was found as resistant for the aedes aegyptiin Brazilian study, ${ }^{17}$ it is used in Dhaka as efficient in mosquito eradication program.

\section{CONCLUSIONS}

The effectiveness of the pesticide and insecticide implemented in the 'Crush programme' to eradicate mosquitoes in Dhaka, is promising in current setting. The adequate actions taken by both wings of Dhaka City Corporation heralded to alter the mosquito breeding and growth, thus improving the public health in general. Nonetheless, it could in effect control the vector borne diseases, such as Dengue, Malaria, Filaria, Chikungunya and many other potential life threatening illnesses among Dhaka dwellers and prevent the devastating after effect by reducing the burden of these diseases.

\section{REFERENCES}

1. Kazi Anis Ahmed, Dhaka tribune (2021), Two city corporation, a ministry fighting to end mosquito menace, 8/C, FR Tower, Panthapath, Dhaka 1207, Bangladesh. 08/03/2021, Retrieved from https: //www.dhakatribune.com/bangladesh/dhaka/2021/0 3/07/2-city-corporations-a-ministry-fighting-to-endmosquito-menace.

2. Rahman N. (2021), Climate and health adaptation planning guide for Dhaka Communities regarding Mosquito control, Dhaka, Bangladesh, 18/03/2021, DOI: 10.13140/RG.2.2.13694.41288.

3. Chiran M. (2021), Mosquito menace on the rise: Dhaka residents take it upon themselves as authorities' efforts not adequate; experts for integrated vector management system. The daily Star 08/03/2021, retrieved from https://www.thedailystar. net/city/ news/mosquito-menace-the-rise-2044909.

4. Tithila K. K., The Dhaka Tribune (2019), Majority of insecticides used by Dhaka city corporations ineffective against mosquitoes, 08/03/2021, retrieved from https://www.dhakatribune.com/bangladesh/ dhaka/2019/07/16/majority-of-insecticides-used-bydhaka-city-corporations-ineffective-against-mosquitoe. 
5. Masum O., bdnews24.com (2019), Dhaka mosquitoes are insecticide-resistant, icddr,b study finds, 08/03/2021, retrieved from https://bdnews 24 . com/bangladesh/2019/06/27/dhaka-mosquitoes-are-i nsecticide-resistant-icddrb-study-finds.

6. From malaria control to eradication: The WHO perspective,(2017), Global Malaria Programme, World Health Organization, 20 Avenue Appia, 1211 Geneva 27, Switzerland.https://doi.org/10.1111/ j.1365-3156.2009.02287.x.

7. Ameen, M., Hossain, M.I. and Chowdhury, M.A. (1999), Integrated mosquito management in Dhaka city: Promising non-chemical components. In Proceedings of the $3 \mathrm{rd}$ international conference on urban pests (pp. 447-56). Graficke zadovy Hronov.

8. Alonso, P., Engels, D. and Reeder, J. (2017), Renewed push to strengthen vector control globally. Lancet, 389(10086), pp.2270-2271.

9. Dhaka Tribune (2020), Taposh: DSCC ready to fight Mosquito menace, UNB. Kazi Anis Ahmed2A Media Limited.8/C, FR Tower, Panthapath, Dhaka 1207, Bangladesh. Retrieved from https://www. dhaka tribune.com/bangladesh/dhaka/2020/06/30/taposh-d scc-ready-to-fight-mosquito-menace.

10. Anna Smyrk, World Health Organization (WHO), (2014), Mosquito fogging will not harm you, reminds WHO and Solomon Islands Ministry of Health, 08/03/2021, retrieved from https://www.who. int/westernpacific/about/how-we-work/pacific-suppo $\mathrm{rt} /$ news/detail/05-05-2014-mosquito-fogging-will-no t-harm-you-reminds-who-and-solomon-islands-minis try-of-health.

11. Bashar, K., Shamsuzzaman, M. and Chowdhury, M.A.K., (2006). Container breeding mosquitoes in Dhaka city, Bangladesh. Bangladesh J Life Sci, 18(1), pp.69-78.
12. Novaluron: Prospects and Limitations in Insect Pest Management, G. Christopher Cutler1 and Cynthia D. Scott-Dupree, Pest Technology, 2007 Global Science Books.

13. World Health Organization (WHO) (2008), Novaluron in Drinking-water: Use for Vector Control in Drinking-water Sources and Containers Background document for development of WHO Guidelines for Drinking-water Quality, WHO Document Production Services, Geneva, Switzerland.

14. Food and Agriculture Organization of the United Nations (FAO)(2004), Specification and Evaluations for Novaluron, 08/03/2021, retrieved from http://www.fao.org/fileadmin/templates/agphome/do cuments/Pests_Pesticides/Specs/novaluro.pdf.

15. N.E.H. Djeghader, L. Aïssaoui, K. Amira and H. Boudjelida (2014), Impact of a Chitin Synthesis Inhibitor, Novaluron, on the Development and the Reproductive Performance of Mosquito Culex pipiens, World Applied Sciences Journal 29 (7): 954-960, 2014, ISSN 1818-4952, IDOSI Publications, DOI: 10.5829/idosi.wasj.2014. 29.07. 82190

16. The Business standard (2021), DNCC mayor urges asthma patients to stay indoors during mosquito control campaign: The mosquito eradication campaign will begin from 8 March for 10 consecutive days. 08/03/2021, Retrieved from https:// tbsnews.net/bangladesh/dncc-mayor-urges-asthma-pa tients-stay-indoors-during-mosquito-control-campaig n-211738.

17. Lima JB, Da-Cunha MP, Da Silva RC, et al. (2003). "Resistance of Aedes aegypti to organophosphates in several municipalities in the State of Rio de Janeiro and Espírito Santo, Brazil". Am. J. Trop. Med. Hyg. 68 (3): 329-33. PMID 12685640. 